\title{
Subdural Haematoma (SDH) Leading to Subfalcine Herniation in a Case of End Stage Renal Disease
}

\author{
Amol Andhale ${ }^{1}$, Sourya Acharya ${ }^{2}$, Kanchan Devde $^{3}$, Yash Gupte ${ }^{4}$, Sree Karthik Pratapa ${ }^{5}$
}

1Department of Medicine, Datta Meghe Institute of Medical Sciences (Deemed to Be University), Sawangi (Meghe), Wardha, Maharashtra, India. ${ }^{2}$ Department of Medicine, Datta Meghe Institute of Medical Sciences (Deemed to Be

University), Sawangi (Meghe), Wardha, Maharashtra, India. ${ }^{3}$ Department of Medicine, MGM Medical College, Aurangabad, Maharashtra, India. ${ }^{4}$ Department of Medicine, Datta Meghe Institute of Medical Sciences (Deemed to Be University), Sawangi (Meghe), Wardha, Maharashtra, India. ${ }^{5}$ Department of Medicine, Datta Meghe Institute of Medical Sciences (Deemed to Be University), Sawangi (Meghe), Wardha, Maharashtra, India.

\section{INTRODUCTION}

Subdural haematoma (SDH) is characterized by bleeding into the sub dural space surrounding the brain. It is mostly associated with atraumatic brain injury. It usually results from tears in bridging veins that cross the subdural space. ESRD is a risk factor for SDH. Coagulation abnormalities, volume overload, haemodialysis and platelet dysfunction predispose to SDH in ESRD and increase the morbidity and mortality. ${ }^{1}$ We report a case of a 44-year-old female, a known case of chronic kidney disease on maintenance haemodialysis who developed SDH with resulting subfalcine herniation.

\section{PRESENTATION OF CASE}

A 44 year old female, known case of chronic kidney disease on thrice a week haemodialysis since 1 year presented to us with a complaint sudden onset of drowsiness since 1 day. There was no history of fever, headache, vomiting, and convulsions.

On examinations - Pulse 58 / min, respiratory rate 12 / min, blood pressure 200 / $110 \mathrm{~mm}$ of $\mathrm{Hg}, \mathrm{SpO}_{2}$ at room air $92 \%$. CNS examination revealed; Glasgow Coma Scale - 11, III nerve palsy of right eye, left sided hemiparesis with extensor plantar response on left side. (Figure - $1 \mathrm{a}, \mathrm{b}$ )

Urgent non contrast CT scan of the brain was done which revealed; evidence of crescent shape mixed density predominantly hypodense collection in right frontotemporo-parietal region of approximate size of $13.2 \times 9.3 \times 2.4 \mathrm{cms}$. (volume 147.3 $\mathrm{cc}$ ), causing mass effect in from of buckling of grey white matter junction and compression of ipsilateral ventricle. There is evidence of midline shift of $18 \mathrm{~mm}$ to left side. Resulting into subfalcine herniation. (Figure 2) Urgent decompressive craniotomy was done with haematoma evacuation.
Corresponding Author:

Dr. Amol Andhale,

Resident, Department of Medicine, DMIMS (Deemed to Be University),

Sawangi (Meghe), Wardha,

Maharashtra, India.

E-mail:dramoljnmc@gmail.com

DOI: $10.14260 / \mathrm{jemds} / 2020 / 638$

How to Cite This Article:

Andhale A, Acharya S, Devde $K$, et al. Subdural haematoma (SDH) leading to subfalcine herniation in a case of end stage renal disease. J Evolution Med Dent Sci 2020;9(39):2919-2920, $10.14260 / \mathrm{jemds} / 2020 / 638$

Submission 17-04-2020,

Peer Review 19-08-2020,

Acceptance 25-08-2020,

Published 28-09-2020.

Copyright (C) 2020 Amol Andhale et al. This is an open access article distributed under Creative Commons Attribution License [Attribution 4.0 International (CC BY 4.0)] 

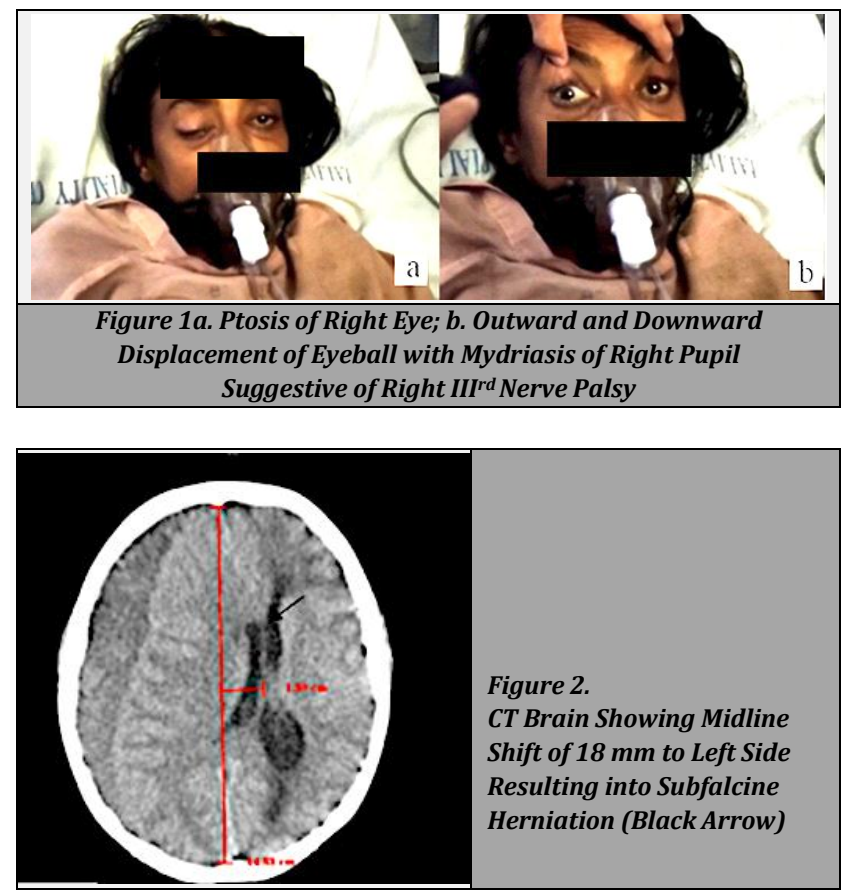

\section{DISCUSSION}

Cerebral tissue shifting from its normal location refers to cerebral herniation that results in mass effect in adjacent space. Subfalcine herniation, also known as cingulate hernia, is the most common form of cerebral herniation. It is generally caused by unilateral frontal, parietal or temporal lobe disease that creates a mass effect due to raised intra cranial pressure resulting in medial shift of the ipsilateral cingulate gyrus beneath the free edge of the falx cerebri. SDH is 4.47 -fold higher in the haemodialysis patients with a thirty-day mortality of approximately $40 \% .^{1,2}$ The incidence of the SDH is more in ESRD and haemodialysis patients as compare to general population.

ESRD patients on long term haemodialysis are usually volume overloaded. This volume overload state causes venous hypertension and with superadded platelet dysfunction and use of heparin in haemodialysis leads to small venous tears of dural bridging veins causing SDH. ${ }^{3}$ Herniation of brain tissue is a life-threatening condition that requires immediate diagnosis and treatment. Subfalcine herniation caused by midline brain shift may result in compression of anterior cerebral artery branches against the fixed falx cerebri, causing infarcts in an anterior cerebral artery distribution. ${ }^{4}$ Evacuation of haematoma by craniotomy or craniectomy is the treatment of choice.

Financial or Other Competing Interests: None.

\section{REFERENCES}

[1] Wang IK, Lin CL, Wu YY, et al. Subdural haematoma in patients with end-stage renal disease receiving haemodialysis 2014;21(6):894-900.

[2] Aguilar MI, Hart RG, Kase CS, et al. Treatment of warfarinassociated intracerebral haemorrhage: literature review and expert opinion. Mayo Clin Proc 2007;82(1):82-92.

[3] Sood P, Sinson GP, Cohen EP. Subdural haematomas in chronic dialysis patients: significant and increasing. Clin J Am Soc Nephrol 2007;2(5):956-9.

[4] Mashour GA, Schwamm LH, Leffert L. Intracranial subdural haematomas and cerebral herniation after labor epidural with no evidence of dural puncture. Anesthesiology 2006;104(3):610-2. 